\title{
Corpo, comida e cultura: Discussão e problematização os padrões contemporâneos de beleza/saúde no ensino de ciências ${ }^{1}$
}

\author{
Tatiana Souza de Camargo*
}

Nádia Geisa Silveira de Souza**

\begin{abstract}
Resumo
A educação escolarizada tem abordado o corpo humano como fenômeno puramente biológico, um conjunto de sistemas e órgãos do qual se estudam características e funcionamentos, sem abordar aspectos sócio/histórico/culturais que o inscrevem constantemente. Atualmente, os meios de comunicação divulgam muitas informações a respeito do corpo. Elas propõem padrões de aparência que investem na magreza e juventude como sinônimos de saúde, responsabilizando o indivíduo pela administração de seu corpo. Entendendo a escola como um espaço privilegiado no aprendizado de conhecimentos sobre o corpo e seus cuidados, discutimos a necessidade de nela pensarmos o corpo em contínua construção, trazendo neste artigo o relato da experiência realizada em oficinas para estudantes de Pedagogia, cujo objetivo foi desenvolver abordagens complexas à temática da alimentação. Sem a intenção de prescrever novos modelos para o ensino de ciências, acreditamos que com esse tipo de estudo, talvez, possamos contribuir com outras formas de compreensão do corpo, não como acontecimento inevitável e estabilizado na história, mas como efeito das circunstâncias vividas e que pode, portanto, ser criticado e recriado de outras maneiras.
\end{abstract}

Palavras-chave: ensino de ciências - corpo - alimentação

\section{Body, food and culture: Discussion and problematization of the contemporary beauty/health standards in science education}

\begin{abstract}
School education has been teaching the human body as purely biological phenomenon, a set of systems and organs, concerning about its characteristics and functioning, without addressing its socio/historical/cultural. Currently, the media shows a lot of information about the body. Its propose standards of appearance that invest in thinness and youth as synonymous of health, blaming the individual for the administration of his/her body. Understanding the school as a privileged space of learning of knowledges about the body and its care, we discussed the need to consider the continuous body construction, bringing in this article the story of experience held in workshops for students of pedagogy, whose goal was to develop complex thematic approaches to food. Without the intent to prescribe new models for the science education, we believe that this type of study may be able to contribute with other forms of understanding the body, not as an event inevitable and stabilized in history, but the effect of circumstances lived and which can, therefore, be criticized and recreated in other ways.

Keywords: science education - body - alimentation
\end{abstract}




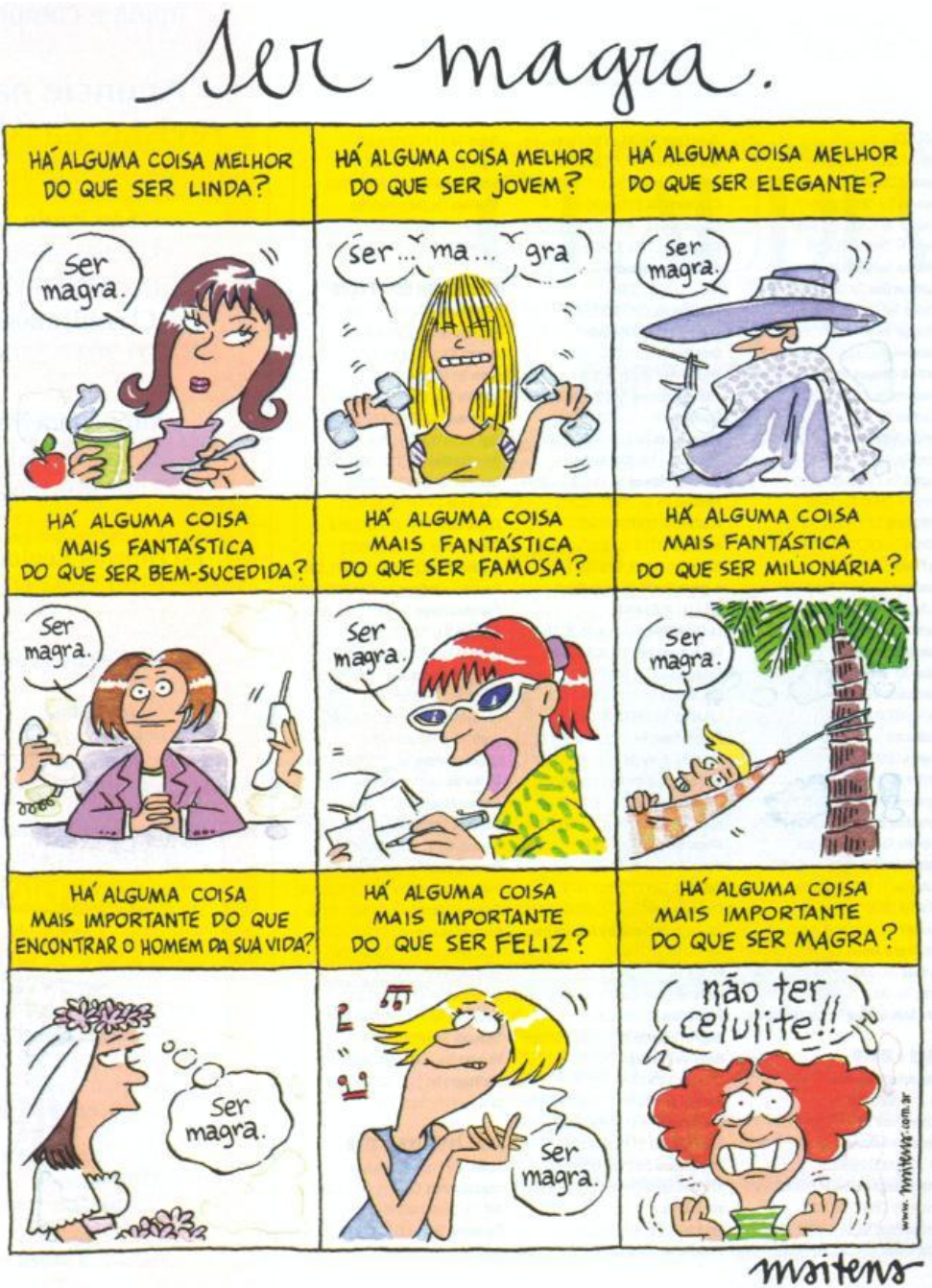

\section{Introdução}

Exageros à parte, o humor desta história em quadrinhos se constrói com base num conjunto de valores e sentimentos partilhados por muitas pessoas, na atualidade - especialmente as mulheres. Nas sociedades como a brasileira contemporânea, os conceitos de saúde e de cuidados com o corpo tornaram-se centrais no processo de construção das subjetividades (CAMARGO, 2012). Nesse sentido, o corpo ideal passou a ser o corpo civilizado, controlado racionalmente; na mesma medida em que os seu cuidados passaram a ter o objetivo de manter a boa saúde e aumentar a longevidade, sem muitos questionamentos sobre as condições e demandas dessa manutenção. Dessa forma, os cuidados de si despendidos a esse corpo passaram a estruturar-se a partir da tríplice "exercício = boa forma $=$ saúde" (LUPTON, 1995: 71). E possuir esta saúde - espécie de bem cuja posse necessita ser constantemente reafirmada; que é tornada visível através do corpo magro, firme e exercitado parece ser uma questão de bom gosto, de autonomia, de desenvolvimento pessoal.

Tal modelo de cuidados corporais contribuíram /para que, em 2006, o Brasil fosse considerado o maior consumidor per capita de medicamentos para emagrecer $(9,1$ doses diárias por mil habitantes), sendo seguido pelos Estados Unidos $(7,7)$ e a Argentina (6,7), de acordo com um relatório elaborado pela Organização Mundial da Saúde, divulgado pelo Instituto Brasileiro de Opinião Pública e Estatística (IBOPE, 2007). Ainda nesse sentido, na pesquisa global realizada pela Sociedade Internacional de Cirurgia Plástica, relativa aos dados do ano de 2009, o Brasil ficou em segundo lugar no número de procedimentos cosméticos cirúrgicos e não cirúrgicos, e foi o país que realizou o maior número de lipoaspirações (ISAPS, 2010). Nesta direção, um estudo realizado em Porto Alegre, com mulheres de 12 a 29 anos, mostrou que somente um terço das que desejavam emagrecer apresentavam IMC2 compatível com excesso de peso (NUNES et al, 2003). Por outro lado, pesquisas realizadas em diferentes cidades brasileiras, incluindo capitais e cidades do interior, com crianças e adolescentes em idade escolar, apresentaram altos percentuais de entrevistados insatisfeitos com seu corpo (FERNANDES, 2007; TRICHES, GIUGLIANI, 2007; PINHEIRO, GIUGLIANI, 2006; 
PINHEIRO, GIUGLIANI, 2006b).

Com base nestes dados, entendemos que, mais do que a supervalorização da magreza, o que acontece na sociedade brasileira atual é a aversão à gordura, ao gordo - uma lipofobia. Em meus trabalhos venho utilizando o conceito de lipofobia como a atitude de busca incessante pela magreza e, ao mesmo tempo, de rejeição quase maníaca à obesidade e ao obeso, num sentido próximo ao proposto por Fischler (1995).

Diante disso, acreditamos que a problematização de tais padrões de beleza/saúde/magreza aliada a discussão dos modelos de cuidados corporais da atualidade apresentam-se como um assunto de relevância política para a área da educação e da promoção da saúde no Brasil, considerando que discursos contemporâneos em torno de um corpo padrão de beleza/saúde vêm gerando, de modo crescente, sentimentos de insatisfação das pessoas em relação ao próprio corpo.

A escola, como um espaço privilegiado no aprendizado de conhecimentos sobre o corpo e seus cuidados, pode contribuir bastante para que se estabeleça tal espaço de problematização e discussão, desde que sejam incorporadas outras abordagens e temáticas ao currículo escolar tradicional. No sentido de se pensar um ensino de ciências que trabalhe com uma noção mais complexa deste fenômeno biossocial que é o corpo, trazemos, nesse artigo, um relato e algumas discussões relevantes acerca de um conjunto de atividades, organizadas em uma oficina, que temos realizado com alunos do curso de graduação em Pedagogia, da Faculdade de Educação da UFRGS, voltada à problematização e desnaturalização dos modelos e prescrições de cuidados com a alimentação e com o corpo na atualidade - o que passamos a narrar e discutir.

\section{O corpo como uma construção biossocial: discutindo algumas estratégias para o ensino escolar}

Esse foi o título atribuído a atividade, na modalidade de oficina, que realizamos com os alunos do curso de Pedagogia, sendo que alguns deles já atuavam como professores.

Nessa oficina, a temática da alimentação, compreendida como uma atividade cotidiana, contínua e universal, que alia aspectos biológicos da nutrição a componentes culturais e simbólicos, ao atuar na constituição dos corpos (FISCHLER, 1990; MACIEL, 1996), foi escolhida como eixo orientador de diferentes atividades. Tínhamos como principais propósitos pensar sobre a possibilidade de outras abordagens para a temática da alimentação, que tratem dos hábitos alimentares como construção, dos gostos como aprendizagens e suas influências nos processos fisiológicos da digestão, dos cuidados com a alimentação e o corpo, presentes na mídia, como práticas a serem debatidas e questionadas.

O ponto de partida foi uma discussão breve de como os temas alimentação e corpo são mostrados nos Parâmetros Curriculares Nacionais do Ensino Fundamental (Ciências Naturais, Meio Ambiente e Saúde Séries Iniciais e Finais), com o propósito de analisar os discursos presentes nessas proposições curriculares e apontar as possíveis e necessárias articulações com as culturas, as sociedades e o consumo.

Discutimos que, especialmente nos Parâmetros Curriculares voltados ao ensino nas Séries Iniciais, a abordagem feita ao tema da alimentação restringe-se aos seus aspectos nutricionais (componentes nutricionais, dieta saudável, etc.), às suas ligações com a higiene e prevenção de doenças, e ao seu significado ecológico (teia alimentar). Nos Parâmetros Curriculares voltados para as Séries Finais, apesar de a abordagem concentrar-se nos mesmo temas indicados para as Séries Iniciais, são traçadas algumas relações com aspectos sócio-culturais da alimentação, chamando a atenção principalmente para as questões de consumo e a influência do marketing no desenvolvimento de hábitos alimentares considerados "inadequados".

Dessa forma, os Parâmetros Curriculares Nacionais do Ensino Fundamental, sejam os das Séries Iniciais ou os das Finais, ao trabalharem as relações entre alimentação e corpo, ainda centram-se na idéia do organismo biológico e deixam de problematizar as múltiplas e cotidianas interpelações sofridas pelos corpos dos estudantes, dos professores, dos pais, como os enunciados de corpo magro/jovem/saudável mostrados em revistas, rótulos de alimentos, propagandas, e que propõem uma gama de práticas das quais os indivíduos devem lançar mão na busca por sua adequação corporal e identitária; o que supostamente o levaria à integração ao grupo socialmente mais valorizado e feliz; a constituir-se como o sujeito que tem consigo próprio o cuidado adequado; que gosta de si mesmo, que se cuida e que está sempre alerta (MISKOLCI, 2006).

Após essas discussões passamos à realização de atividades em grupos. As oficinas foram filmadas, e os materiais produzidos pelos participantes foram fotocopiados ou fotografados.

\section{Gostar dos alimentos}


Esse foi o nome dado à primeira atividade. Nela o grupo deveria discutir por que comemos. Após a discussão, cada componente do grupo, individualmente, fecharia os olhos e procuraria lembrar-se de um alimento de que gosta, anotando o alimento, as lembranças e as sensações que teve.

A seguir, ao olhar para os alimentos oferecidos - chocolate, barra de cereais, copo de água e fruta - cada componente do grupo prestaria atenção em alterações ocorridas em seu corpo, anotando as percepções. Em seguida, cada um/a morderia e mastigaria os alimentos e tomaria água, prestando atenção ao que ocorre e deveria contar aos demais componentes do grupo o que percebeu daquilo que ocorreu na boca e no trajeto dos alimentos ao serem deglutidos, anotando o que estava sendo dito.

O grupo deveria, ainda, discutir sobre o trajeto que os alimentos fazem no corpo para serem utilizados na nutrição e depois eliminados. Por fim, deveriam produzir um cartaz mostrando o trajeto do alimento para ser utilizado e eliminado pelo corpo, para posterior explicação no grande grupo.

Nas discussões sobre por que comemos, os integrantes do grupo enfatizaram o aspecto da comensalidade, da convivialidade. Reportaram memórias de família, as lembrança do gosto
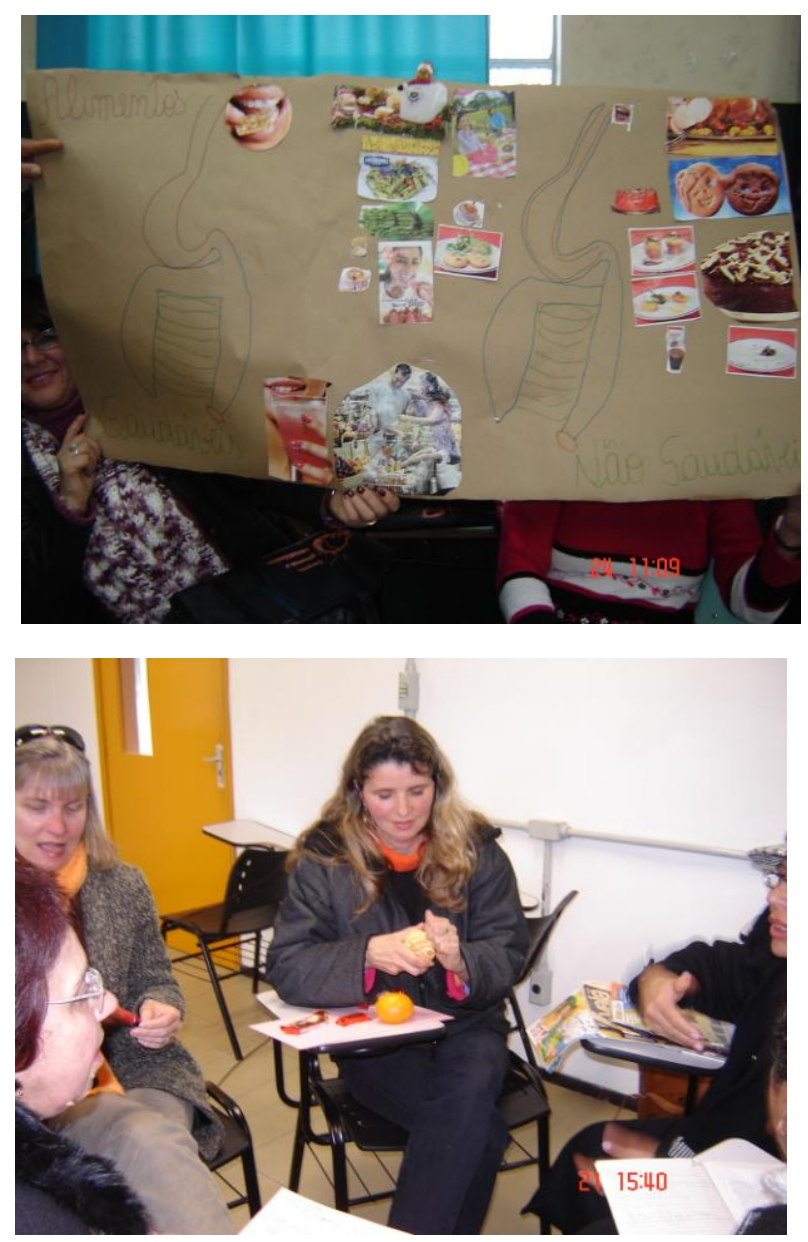

inesquecível da comida da avó. Além disso, ressaltaram a refeição como uma oportunidade de reunião com a família. Alguns integrantes comentaram que podemos comer também por ansiedade e para suprir "carências emocionais" neste caso, dando preferência para comidas específicas que parecem oferecer uma sensação de conforto, como o chocolate. O prazer também foi apontado como um dos motivos pelos quais comemos, mas estando sempre ligado com uma idéia de culpa - caso do leite condensado, narrado como um alimento bastante calórico, que na infância era uma comida muito prazerosa e que, para os integrantes do grupo, tem agora um sentido de "pecado".

Cabe destacar que, embora todos os participantes tivessem escolarização em nível superior e atuassem como professores, a maioria teve dificuldades em dizer o que acontece com o alimento até o nível do estômago, poucos falaram sobre os processos acontecidos nos intestinos e menos ainda foram os que conseguiram relacionar a absorção de nutrientes com circulação e respiração celular. Isso mostra, em certa medida, que as abordagens escolarizadas do corpo pouco contribuem para que as pessoas conheçam tanto os processos que ocorrem nos seus corpos, quanto as relações existentes entre eles e também com o meio.
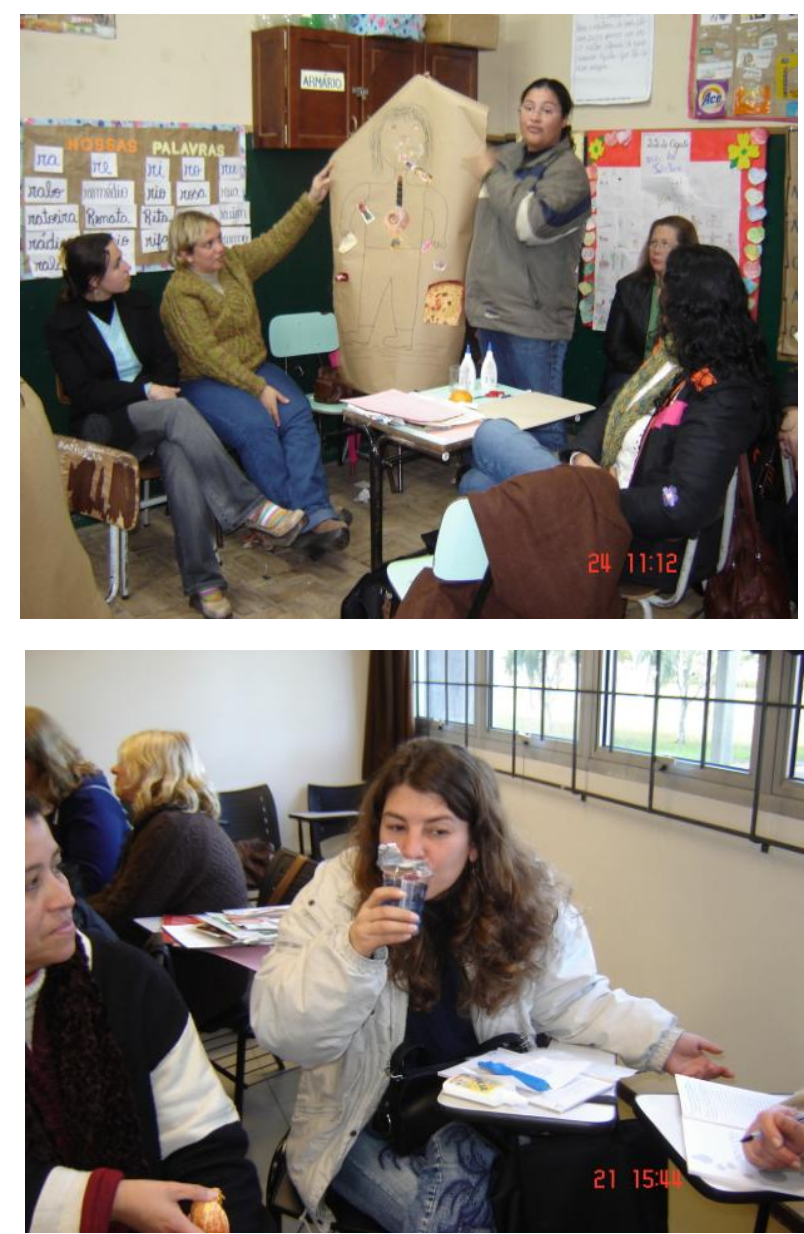

Horizontes, v. 30, n. 2, p. 69-79, jul./dez.2012 
Figuras 1-4: Atividade "Gostar dos alimentos"

Figuras 1 e 2 (acima): Consumindo os alimentos oferecidos.

Figuras 3 e 4: Cartazes produzidos na atividade.

Essa atividade visava gerar discussões a respeito da construção do hábito alimentar, dos gostos (por exemplo, não gostar de verduras associado a seu uso na alimentação de animais), os comportamentos, os horários, os modelos, os motivos - nos âmbitos da cultura, da família, da mídia, da tradição regional, enfim, num processo histórico-social. A alimentação geralmente abordada na sala de aula a partir do discurso biomédico da nutrição e da saúde considera apenas aspectos da dieta equilibrada e da anatomo-fisiologia do sistema digestivo, megligenciando esses outros saberes construídos em outras vivências sociais.

Outro aspecto tratado nesta atividade refere-se às percepções de que as manifestações fisiológicas do corpo - por exemplo, as modificações no sistema digestivo - encontram-se em interrelação com o meio e outros órgãos - os olhos (o visual), o nariz (o olfato), o cérebro (a memória, as lembranças, a identificação de sensações). Ou seja, as modificações no sistema digestivo iniciam antes de comermos os alimentos, integrando não só o funcionamento do corpo, mas também elementos aprendidos nas práticas culturais. Essa atividade visava, ainda, a discutir as noções dos participantes sobre os motivos pelos quais comemos: saciar a fome, prazer, ansiedade, suprir necessidades energéticas e funcionais, crescimento, entre outros citados.

\section{Escolhas alimentares}

Este foi o nome dado à segunda atividade, que se dividia em três etapas. Em uma primeira etapa, os integrantes do grupo deveriam imaginar que estavam na hora do almoço. Deveriam então, montar um prato (desenho, figuras, palavras) com aqueles alimentos que geralmente compõem o almoço de cada um deles durante a semana. Após a montagem do prato, eles deveriam explicar as escolhas dos alimentos a serem ingeridos.

$\mathrm{Na}$ segunda etapa, os integrantes do grupo deveriam imaginar que estavam encarregados da organização de uma festa, em que cada um/a ficaria responsável por levar um prato. Deveriam, então, imaginar qual prato cada um dos integrantes do grupo levaria. Em seguida, montariam um cardápio para a festa a ser apresentado no grande grupo, explicando os motivos da escolha desses pratos.

$\mathrm{Na}$ terceira etapa, o grupo deveria examinar rótulos de alimentos, buscando observar como essas produções midiáticas abordam os temas da alimentação e do corpo.

$\mathrm{Na}$ discussão sobre a montagem dos pratos cotidianos, o critério saúde foi ressaltado pelos integrantes do grupo como o principal definidor de suas escolhas alimentares. Cabe salientar que, no entanto, nenhum dos pratos por eles montados seguia as normas de prescrição nutricional - tinham, por exemplo, carboidratos em excesso e poucos incluíam legumes e/ou verduras.

$\mathrm{Na}$ definição do cardápio da festa, a lógica da escolha dos alimentos pareceu modificar-se. Se na alimentação diária a saúde é narrada como principal preocupação, na festa o prazer é o critério privilegiado.

Ao analisarem as embalagens, os integrantes do grupo apontaram o discurso apelativo presente em embalagens de salgadinhos, biscoitos recheados (as ditas "porcarias"), que incitaria, principalmente as crianças e adolescentes, ao seu consumo. No entanto, não reconheceram que nos rótulos de alimentos ditos "saudáveis" - como cereal matinal light, pão integral - está presente outro tipo de discurso que, apelando para a exigência da saúde/beleza do corpo, busca construir o alimento como uma espécie de "remédio".

Nessa atividade nosso propósito era discutir os aspectos sociais implicados nas nossas escolhas alimentares, tais como as rotinas de trabalho - que em alguns casos (estudantes que moravam e trabalhavam em uma cidade pequena) ofereciam a possibilidade de realizar um almoço do tipo refeição, até mesmo em casa, e em outros casos só possibilitavam a realização de um almoço do tipo fast-food (estudantes que moravam e trabalhavam em cidades grandes); a necessidade da praticidade; a disponibilidade da região, da estação do ano e de poder aquisitivo; os gostos aprendidos no âmbito da família. 

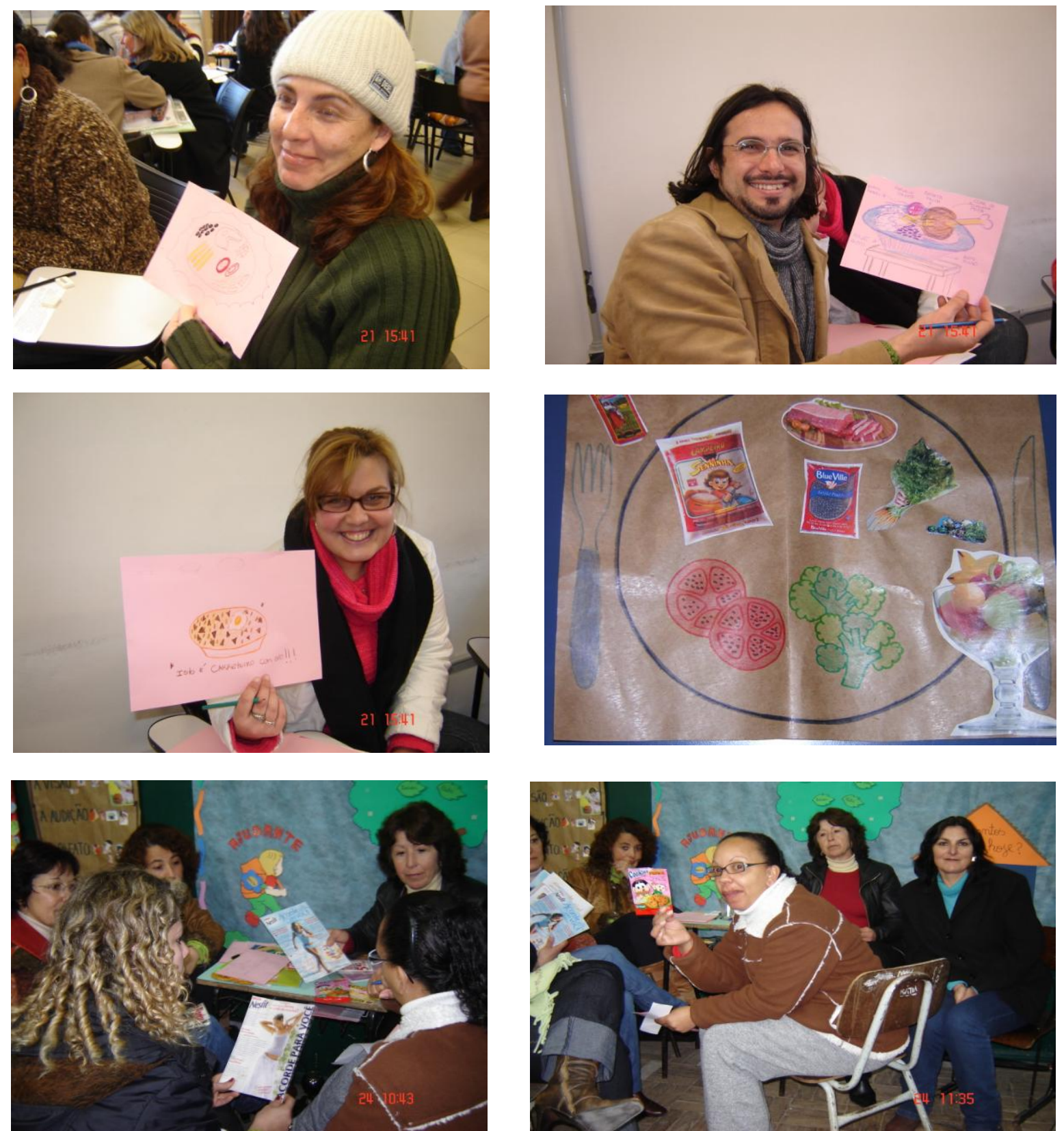

Figuras 5 - 10: Atividade "Escolhas alimentares"

Figuras 5, 6, 7 e 8 (acima): Montagem do prato de almoço.

Figuras 9 e 10: Observação e discussão dos rótulos de alimentos.

\section{Olhando o corpo}

Esse foi o nome dado à terceira atividade, composta também por três etapas. Na primeira etapa, os integrantes do grupo deveriam observar as imagens de corpo veiculadas em revistas feminina - Boa Forma, Corpo e Beleza, Celulite, Saúde da Mulher, Capricho - e em seguida discutir como tais imagens levam cada um/a a pensar sobre seu corpo e a se sentir . Deveriam anotar pensamentos e sentimentos que lhes ocorreram ao olhar as imagens de corpo e as "receitas" de saúde e beleza presentes nestas revistas.

Em seguida, na segunda etapa, deveriam dizer se, caso pudessem, gostariam de modificar algo no seu corpo ou no modo de cuidar de si. Cada um deveria anotar o que mudaria no seu corpo.

Na terceira etapa, deveriam discutir sobre qual seria a idéia de corpo "ideal" para o grupo. Em seguida, deveriam produzir um cartaz construindo o modelo de corpo ideal com recortes de revistas que mostrem partes do corpo que atendam a tal modelo.

Neste grupo, todas as integrantes eram mulheres. Todas elas disseram não se identificar de nenhuma forma com as figuras femininas mostradas nas revistas. Disseram sentir-se enganadas ao olhar as promessas de dietas e 
relatos presentes nas revistas. Além disso, relataram não ter vontade e condições financeiras para buscar o "corpo perfeito", e que para elas isso não representava um objeto de preocupação. Apesar disso, quando questionadas a respeito das modificações que fariam em seus

corpos e nos cuidados consigo, elas buscam aproximar-se do padrão de saudável/belo. Relatam que gostariam de ter hábitos alimentares mais saudáveis, que gostariam de poder comer de tudo sem engordar e de que gostariam de ter mais disciplina para praticar atividades físicas.
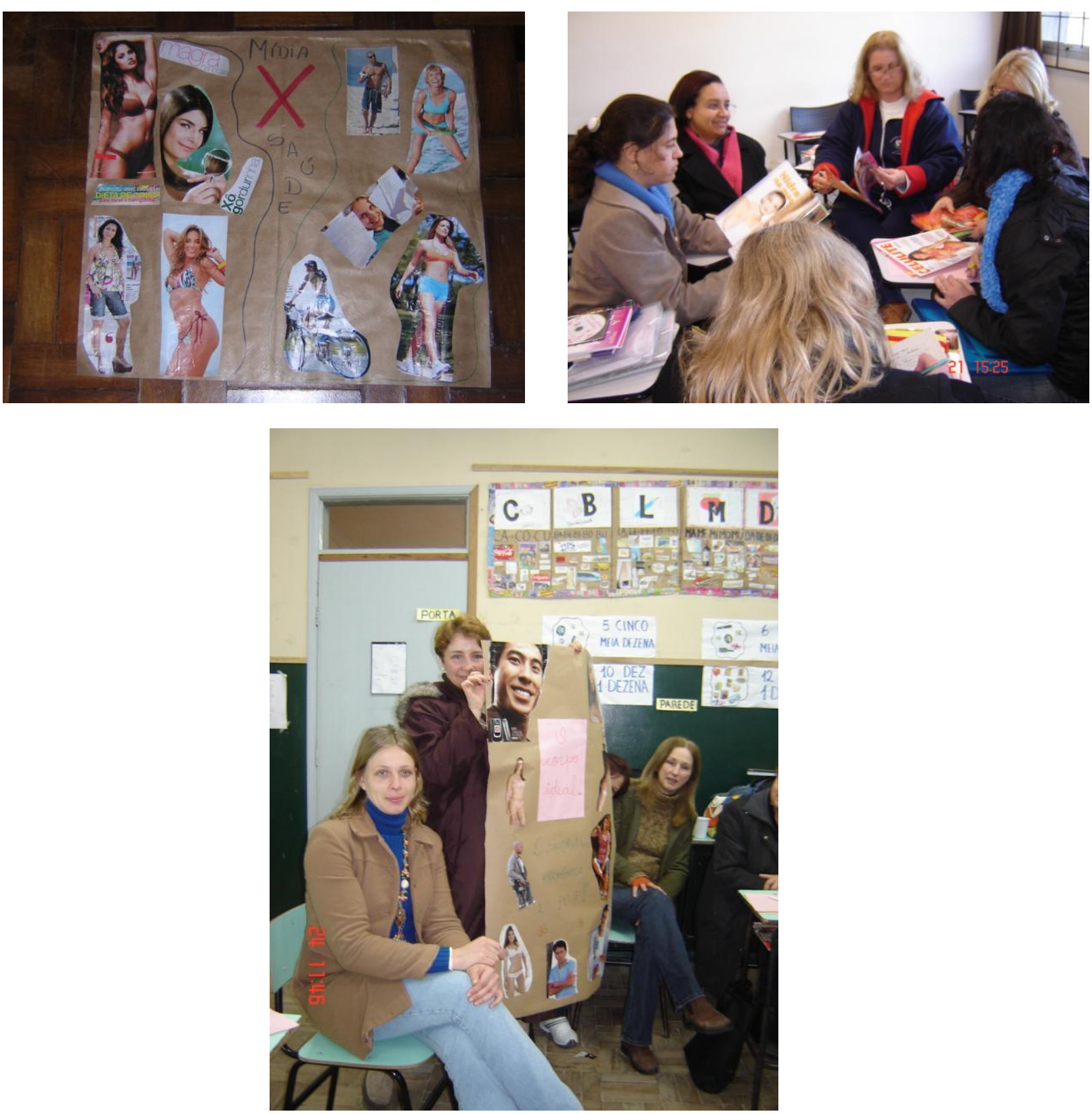

Figuras 11 - 13: Atividade "Olhando o corpo"

Figura 12: Observação, leitura e discussão das revistas.

Figuras 11 (acima à esquerda) e 13 (abaixo): Cartazes

"Corpo Ideal" produzidos na atividade.

Nosso principal objetivo com essa atividade era o de tornar visíveis os padrões veiculados pela mídia, especialmente em revistas femininas, que cotidianamente nos interpelam produzindo sentimentos, atitudes, valores, modos de pensar acerca do nosso corpo, direcionando em certa medida o modo como pensamos e agimos em relação ao nosso corpo.

Além disso, ao mostrar as implicações dos padrões de beleza e saúde relacionados ao cuidado do corpo, pretendíamos chamar a atenção para e problematizar os efeitos de tais discursos, os quais muitas vezes geram excessos de exercícios físicos, de cirurgias plásticas, de 
consumo de medicamentos emagrecedores, de restrições alimentares, e de sentimentos de insatisfação consigo, que também acarretam efeitos de âmbito biológico. Nesse sentido, cabe citar que existem autores da área da Medicina e Bioquímica cujas pesquisas apontam que boa parte dos efeitos comumente associados ao excesso de peso, como a hipertensão e o diabetes, podem ter relações causais com o estresse gerado pela insatisfação corporal - que ativa no organismo uma cadeia de reações prejudiciais (MUENNIG et al, 2008).

Essa atividade nos permitiu, ainda, discutir sobre como a beleza, velhice, juventude, saúde, feminino/masculino, estilo de vida, estética (Cosmetologia, Medicina Estética) aparecem nesses materiais pedagógicos. Dessa forma, tal atividade visou a mostrar as profundas relações entre as práticas sociais e a constituição e funcionamento do corpo, assim como trazer a necessidade de serem realizadas leituras críticas de imagens e anúncios publicitários e reportagens nas práticas escolares, uma vez que tais materiais interpelam e ensinam modos de pensar, agir e sentir com relação ao corpo e a si mesmo.

\section{Considerações Finais}

Nesse artigo buscamos problematizar a maneira tradicional como o corpo é ensinado na educação escolarizada - como um organismo biológico. Nele relatamos nossa experiência na realização de oficinas para estudantes de pedagogia, nas quais buscamos mostrar a importância de trabalhar o corpo como uma construção biossocial em constante transformação. As atividades desenvolvidas nestas oficinas tinham como temáticas a alimentação e suas relações com a constituição dos corpos, discutidas sob vários aspectos, como a construção dos gostos, o aprendizado de hábitos alimentares, as dietas emagrecedoras, entre outros.

Salientamos que, apesar de desapercebida, a insatisfação corporal é experimentada desde a infância; e, na escola, parece ter efeitos amplificados (CAMARGO, 2012). Neste sentido, Wann (2009) cita que, segundo um relatório da Associação Educacional Nacional norteamericana, a vida escolar para os estudantes com excesso de peso é uma experiência de preconceito contínuo, de discriminação desapercebida, e de assédio quase constante. Desde o jardim de infância até o colégio, os estudantes com excesso de peso experienciam o ostracismo, o desencorajamento $\mathrm{e}$ às vezes a violência. "Frequentemente ridicularizados por seus pares e desencorajados até mesmo por bem intencionados profissionais da educação, os estudantes com excesso de peso desenvolvem baixa autoestima e têm horizontes limitados." (WANN, 2009: XIX). Ainda neste sentido, Weinstock e Krehbiel (2009: 124), afirmam que, "apesar de muitos sistemas de discriminação terem sido elucidados e desafiados nas últimas décadas, a aceitação social da discriminação com relação ao excesso de peso continua forte".

Sendo assim, entendemos que a educação escolarizada é um espaço privilegiado no aprendizado de conhecimentos sobre o corpo e os cuidados de si. No entanto, as práticas escolares, especialmente aquelas relacionadas ao ensino de ciências e de biologia, ao centrarem suas abordagens na visão biológica de corpo - presente nos livros didáticos e nos Programas escolares, regida pelas disciplinas acadêmicas -, deixam de incluir em suas discussões os saberes e "conteúdos" produzidos por pedagogias que ensinam "fora" do ambiente escolar. Essa tradição escolar vem impedindo a produção de um outro saber crítico e relevante para a vida das pessoas, capaz de fazer frente às múltiplas "verdades" que inscrevem e regulam os seus corpos.

Em virtude disso, percebemos a necessidade de problematizar as noções biologicistas de corpo e de contribuir para que se pensem outras práticas escolares, capazes de dar voz aos estudantes e de olhar criticamente os efeitos das práticas sociais no modo de pensar das pessoas. Para tanto, entendemos que se torna necessário introduzir na sala de aula a concepção de um corpo marcado pelas práticas, visto que é nelas se adquirimos os sentidos atribuídos aos gestos, aos sentimentos, aos objetos, às pessoas e a si mesmos.

Todavia, isso exige o movimento de interrogarmos sobre a possibilidade de produzir outras formas de nos relacionarmos com os alunos, os saberes, as matérias escolares. $\mathrm{O}$ que talvez crie condições para construirmos outras estratégias de ensino relacionadas às vidas das pessoas, ou seja, o que se apresenta como uma questão política para nós, professores.

\section{Referências Bibliográficas}

CAMARGO, Tatiana Souza. O governo dos excessos - Uma análise das práticas de prevenção e controle do excesso de peso realizadas por profissionais da Atenção Básica à Saúde, em Porto Alegre / RS. Tese (Doutorado) - Faculdade de Educação, Universidade Federal do Rio Grande do Sul, Porto Alegre. 2012. Disponível 
em:

<>http://sabi.ufrgs.br/F/6FJYAGX92DHMACP7

HQRC66AK2BECNCPQA4AE9KNXVJDHITU R8D-

06082? func $=$ service $\&$ doc_library $=U R S 01 \&$ doc $\_n$ umber $=000828934 \&$ line_number $=0001 \&$ func_co $\mathrm{de}=$ WEB-FULL\&service_type $=$ MEDIA. Acesso em: 29 Out. 2012.

Você é o que você come? Os cuidados com a alimentação: implicações na constituição dos corpos. Dissertação (Mestrado) - Instituto de Ciências Básicas da Saúde, Universidade Federal do Rio Grande do Sul, Porto Alegre. 2008. Disponível em: <http://hdl.handle.net/10183/13087>. Acesso em: 14 Ago. 2012.

DUNCAN, Bruce B.; et al. Medicina Ambulatorial: condutas de atenção primária baseadas em evidências. $3^{\mathrm{a}}$. Ed. Porto Alegre: Artmed, 2004.

FERNANDES, Ana Elisa Ribeiro. Avaliação da imagem corporal, hábitos de vida e alimentares em crianças e adolescentes de escolas públicas e particulares de Belo Horizonte. Dissertação (Mestrado) - Faculdade de Ciências da Saúde, Universidade Federal de Minas Gerais. Belo Horizonte: 2007. Disponível em: <<http://hdl.handle.net/1843/ECJS-76KMH6>>. Acesso em: 29 Out. 2012.

FISCHLER, Claude. "Obeso benigno, obeso maligno". In: SANT'ANNA, Denise Bernuzzi de (Org.). Políticas do corpo. São Paulo: Estação Liberdade, 1995. pp. 69-80.

FISCHLER, Claude. L'Homnivore. Paris: Odile Jacob; 1990.

IBOPE. Uma receita de crescimento. Publicado em: 03 Ago 2007. Disponível em: <<http://www.ibope.com.br/calandraWeb/servlet/ CalandraRedirect?temp $=5 \&$ proj=PortalIBOPE $\& p$ $\mathrm{ub}=\mathrm{T} \& \mathrm{db}=\mathrm{caldb} \&$ comp $=$ Not $\%$ EDcias $\&$ docid $=39$ D9D357CF0F629F8325732C006D37>>. Acesso em: 14 Ago. 2012.

ISAPS. Estatísticas sobre cirurgias plásticas em todo mundo disponíveis pela primeira vez. Disponível em: <<http://www.isaps.org/uploads/news_pdf/BIENI AL_GLOBAL_SURVEY_press_release_Latin\%2 0American\%20Portuguese.pdf $\gg$ >. Acesso em: 11 Jun 2012.
LUPTON, Deborah. The Imperative of Health: Public Health and the Regulated Body. London: SAGE, 1995.

MACIEL, Maria Eunice. "Introdução". In: Horizontes Antropológicos, Porto Alegre, Ano 2, $\mathrm{n}^{\circ}$ 4, pp.7-8, 1996.

MISKOLCI, Richard. "Corpos elétricos: do assujeitamento à estética da existência". In: Revista de Estudos Feministas, Dez 2006, vol.14, n 3, p.681-693.

MUENNIG, Peter; et al. "I think therefore I am: perceived ideal weight as a determinant of health". In: American Journal of Public Health, Vol 98, n 3, 2008. p 501- 506.

NUNES, M.A.; BARROS, F.C.; ANSELMO OLINTO, M.T.; CAMEY, S.; MARI, J.D. "Prevalence of abnormal eating behaviors and inappropriate methods of weight control in young women from Brazil: a population-based study". Eating and Weight Disorders. 2003; 8: 100-6.

PINHEIRO, Andréa Poyastro; GIUGLIANI, Elsa Regina Justo. "Body dissatisfaction in Brazilian schoolchildren: prevalence and associated factors". Revista de Saúde Pública, v.40, n.3, $2006 . \quad$ Disponível em: $<<$ http://www.scielo.br/scielo.php?script=sci_artte xt\&pid=S0034-

$89102006000300018 \& \operatorname{lng}=e n \& n r m=i s o \gg$.

Acesso em: 04 Out. 2012

PINHEIRO, Andréa Poyastro; GIUGLIANI, Elsa Regina Justo. "Quem são as crianças que se sentem gordas apesar de terem peso adequado?". In: Jornal de Pediatria, v. $82, n^{\circ} 3$,

2006b. Disponível em: $<<$ http://www.scielo.br/scielo.php?script=sci_artte $\mathrm{xt} \& \mathrm{pid}=\mathrm{S} 0021-$

$75572006000300014 \& \operatorname{lng}=e n \& n r m=i s o>$.

Acesso em 04 Out. 2012.

TRICHES, Rozane Márcia; GIUGLIANI, Elsa Regina Justo. "Body dissatisfaction in school children from two cities in the South of Brazil". In: Revista de Nutrição, Campinas, v. 20, n. 2, $2007 . \quad$ Disponível em: $<<$ http://www.scielo.br/scielo.php?script=sci_artte $\mathrm{xt} \&$ pid=S1415-

$52732007000200001 \& \operatorname{lng}=e n \& n r m=i s o>>$.

Acesso em: 25 Out. 2012.

WANN, Marilyn. "Foreword". In: ROTHBLUM, Esther; SOLOVAY, Sondra (Org.). The Fat 
Studies Reader. Nova Iorque: New York University Press, 2009. p. IX-XXV.

WEINSTOCK, Jacqueline; KREHBIEL, Michelle. "Fat youth as common targets for bullying". In: ROTHBLUM, Esther; SOLOVAY, Sondra (Org.). The Fat Studies Reader. Nova Iorque: New York University Press, 2009. p. 120126. 
Notas

1 Agradecemos aos professores e alunos que, gentilmente, participaram das oficinas e cederam suas imagens para a construção deste artigo.

2 Îndice de Massa Corporal (IMC), eleito em 1994, pela Força-Tarefa Internacional sobre Obesidade, como o índice mais adequado para o diagnóstico de sobrepeso e obesidade entre adultos, tendo seus valores posteriormente adaptados para o uso em indivíduos a partir dos dois anos de idade. O IMC é calculado dividindo o peso do indivíduo (em quilogramas) por sua altura ao quadrado (em metros). A partir do resultado numérico obtido com esse cálculo, são definidas as seguintes categorias: IMC $<18.5=$ baixopeso; 18, 5, < IMC < 24,9 = peso normal; $25<$ IMC $<29,9=$ sobrepeso; $30<$ IMC $<34,9=$ obesidade grau I; $35<$ IMC $<39,9=$ obesidade grau II; $40<$ IMC = obesidade grau III, a chamada obesidade mórbida. Tais categorias foram definidas a partir dos resultados numéricos obtidos do estudo de uma população referência internacional (DUNCAN et al, 2004).

\section{Sobre as autoras:}

Tatiana Souza de Camargo: Pontifícia Universidade Católica do Rio Grande do Sul, Porto Alegre.

Nádia Geisa Silveira de Souza: Universidade Federal do Rio Grande do Sul, Porto Alegre. 